\title{
Industrialization and the Evolution of Enforcement Institutions
}

\author{
Toshihiko Mukoyama \\ University of Virginia \\ tm5hs@virginia.edu
}

\author{
Latchezar Popov \\ University of Virginia \\ lpopov@virginia.edu
}

February 2015

In Progress

\begin{abstract}
We analyze the evolution of economic institution during the process of industrialization. In particular, we focus on the institution of contract enforcement. Empirically, we show that, during the process of industrialization, countries tend to shift their manufacturing production towards industries that require more relationship-specific investment. Theoretically, we build a dynamic model with incomplete contracts and evolving institutions to account for this pattern. In our model, the incompleteness of contract leads to two types of misallocations that leads to production inefficiency: unbalanced use of inputs and unbalanced production of different goods. In addition to this production inefficiency, the imperfect contract enforcement leads to distortions in factor supply. The government invests in enforcement institutions in order to improve the contractual environment, and the evolution of industry composition crucially depends on how contractual environment changes over time.
\end{abstract}

Keywords: Industrialization, Institution, Incomplete contract, Misallocation JEL Classifications: E02, L14, L16, O14, O43 


\section{Introduction}

There is an emerging empirical and theoretical literature that attributes institutions as the fundamental cause of differences in economic development. Acemoglu, Johnson, and Robinson (2005a) summarize empirical evidences and conclude that "differences in economic institutions appear to be the robust causal factor underlying the differences in income per capita across countries" and "Institutions are therefore the fundamental cause of income differences and long-run growth (pp.420-421)." Helpman (2004) writes "institutions that promote the rule of law, enforce contracts, and limit the power of rulers are important for economic development (p.112)."

Much of the recent literature on institution and economic growth is inspired by the pioneering work of Douglass North. North (1990) defines institutions as "Institutions are the rules of the game in a society or, more formally, are the humanly devised constraints that shape human interaction (p.3)." Since the influential work of De Soto (1989) and (2000), it has been widely documented that such "rules of game" vary substantially across countries (Djankov et al. (2002) and (2003)).

In this paper, we focus on one important element of such economic institutions: enforcement of contracts. North (1990) forcefully argues that "the inability of societies to develop effective, low-cost enforcement of contracts is the most important source of both historical stagnation and contemporary underdevelopment in the Third World (p.54)." In particular, our empirical and theoretical analysis consider investment decisions in specific capital under contract incompleteness. When contracts are incomplete (or not enforceable), the efficient level of such investment is difficult to achieve, and this can have an detrimental effect on aggregate output and productivity.

A key to our analysis is that the economic institution evolves over time. In the empirical analysis, we show that, as countries industrialize, they shift production towards industries that requires more specific investments. In the theoretical model, this shift occurs through the gradual improvement of the contractual environment. Our model involves governmental investments that improves the contractual environment, such as better protection of property 
rights and better-functioning courts. This reflects North's (1990) argument that "creating a system of effective enforcement and of moral constraints on behavior is a long, slow process that requires time to develop if it is to evolve (p.60)."

The main contributions of our paper is twofold. First, we document that over the course of their industrialization, countries shift their production to industries that requires more specific investments. Second, we develop a model with endogenous institutions that accounts for this pattern. Our model extends Acemoglu, Antràs, and Helpman's (2007) framework into dynamic environment. We further allow the government to engage in investment that improves contractual environment.

The paper is organized as follows. The next section documents empirical regularities that motivates our theoretical model. Section 3 develops a model of incomplete contracts and endogenous evolution of contractual environment. Section 4 concludes.

\section{Empirical regularities}

In general, the quality of enforcement institutions has pervasive effects throughout the economy, including investment in physical and human capital, entrepreneurship, relationships along the supply chain. Our main focus in this paper is one particular manifestation of distortions due to enforcement frictions - underinvestment in relationship-specific capital.

Production processes in various industries differ in terms of required amount of specific investments (the "contract intensity"). As a result, industries differ in their exposure to enforcement frictions. Therefore, in turn, the industry composition of an economy is affected by the quality of enforcement institutions. In this Section, we empirically describe how the industry composition of the economy changes over the course of industrialization in terms of reliance on specific investment.

We build on the influential work of Nunn (2007). Focusing on international trade, Nunn (2007) empirically shows that better enforcement quality confers comparative advantage in more contract-intensive industries. We utilize his measure of contract intensity in our analysis. Note that our application differs from his analysis in two important dimensions. First, 
Nunn (2007) considers exports, while we are interested in production. Second, the focus of Nunn (2007) is on the cross-sectional patterns of comparative advantage, while we investigate the dynamics of industrial composition.

For a wide category of intermediate inputs, Nunn (2007) computes the fraction of intermediate goods that are nonstandardized (not traded on an exchange and not having a reference price). These intermediate goods correspond to the notion of specific investments. Using the U.S. input-output tables, he constructs a measure of the importance of specific investments in an industry. This measure conforms closely to the way we model contractual incompleteness in the next Section.

In addition to Nunn's measure, we use data on output and value added of industries from the World KLEMS initiative. The initiative coordinates efforts by national and regional database to construct comparable data on output and productivity at the industry level. We combine Nunn's score of contract intensity with output and value added from the KLEMS database to construct weighted scores of contract intensity over time and across countries. ${ }^{1}$ We also use measures of Purchasing Power Parity GDP per capita from the Penn World Tables version 7 . We focus on manufacturing sector, since the structural transformation of an economy (the shift from agriculture to manufacturing to services) occurs with an entirely different mechanism.

Figure 1 plots average contract intensity in manufacturing, weighted by value added in different industries for four countries: the UK, Korea, China, and Poland. We find the following patterns: (1) contract intensity for the already developed countries such as UK does not exhibit a strong trend; (2) countries that industrialize successfully (such as South Korea and China) experience a marked increase in contract intensity over time. Poland has exhibited moderate growth in recent years, but not as rapid as the industrialization of South Korea and China - its contract intensity exhibits an intermediate pattern between the UK and rapidly-growing economies. The next Section constructs a dynamic general equilibrium

\footnotetext{
${ }^{1}$ KLEMS data is in ISIC 3.1 classification at the two-digit level, while Nunn's measure is in the BEA IO classification. We use a crosswalk between the two classifications using NAICS (North American Industry Classification System) with concordances from the BEA and the Census. For more details on the data construction, see Appendix A.
} 


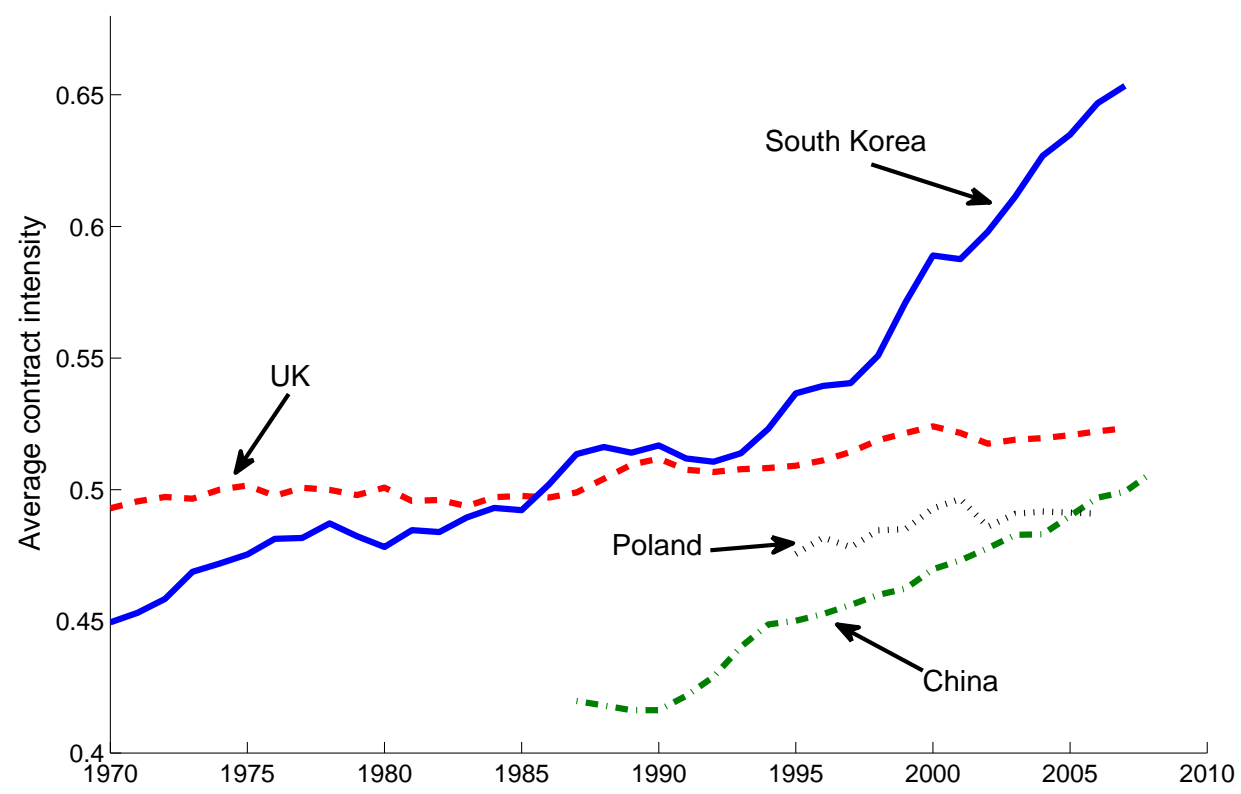

Figure 1: Average contract intensity, weighted by value added

model to interpret this pattern.

Figure 2 uses gross output as a weight and repeats the same exercise as Figure 1 . The same pattern can be observed with this alterative measure.

\section{Model}

Our model extends Acemoglu, Antràs, and Helpman (2007). There are three layers of production: final goods, intermediate goods and raw materials. Final goods are introduced mainly for the ease of accounting, and our main focus is on the differentiated intermediate goods sector. Each intermediate good is produced by a monopolist who has to engage in the production activity with many suppliers. The contract between an intermediate good producer and his suppliers is incomplete, and the degree of incompleteness differ across goods. Therefore, each intermediate good in this model corresponds to each industry in Section 2. We allow this incompleteness to change over time through the government's activities. 


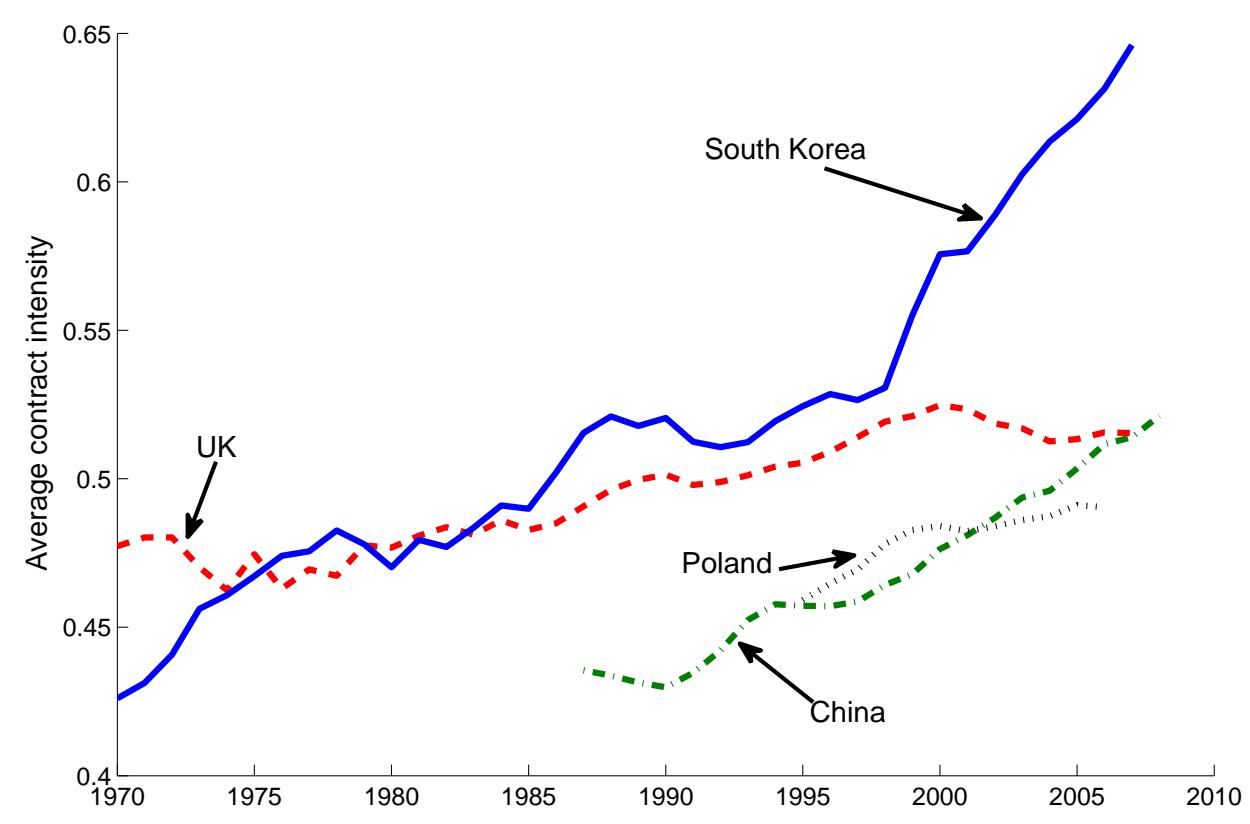

Figure 2: Average contract intensity, weighted by gross output

\subsection{Environment}

The economy consists of a representative consumer and the three sectors of production. The final good can be used for consumption and investment and is the numeraire.

\subsubsection{Consumers}

The representative consumer's utility is

$$
\sum_{t=0}^{\infty} \beta^{t} u\left(C_{t}, 1-L_{t}\right),
$$

where $\beta \in(0,1)$ is the discount factor, $u(\cdot)$ is the period utility function which is strictly increasing and strictly concave, and $C_{t}$ is consumption at time $t$ and $L_{t}$ is the labor supply at $t$. The total time endowment is normalized to one.

The household supplies labor, owns a portfolio of shares of all firms in the economy, and 
owns and accumulates capital. ${ }^{2}$ Hence the budget constraint for the consumer is

$$
K_{t+1}+C_{t}+T_{t}=\left(1+r_{t}-\delta_{K}\right) K_{t}+w_{t} L_{t}+\Pi_{t},
$$

where $K_{t}$ is the capital stock, $T_{t}$ is the lump-sum tax from the government, and $\delta_{K}$ is depreciation rate of capital, $r_{t}$ is the rental rate of capital, and $w_{t}$ is the wage rate. $\Pi_{t}$ is the profit from all firm sectors.

\subsubsection{Raw materials producers}

Raw materials are produced competitively from capital and labor. The representative producer has production function $F(K, L)$ that is constant returns to scale, strictly concave and differentiable.

We also assume standard properties on the marginal product of capital:

$$
\begin{aligned}
& \lim _{K \rightarrow 0} F_{1}(K, L)=\infty, \\
& \lim _{K \rightarrow \infty} F_{1}(K, L)<\delta_{K} .
\end{aligned}
$$

Raw materials are used as inputs by the intermediate goods producers at a price $q_{t}$. Thus, in equilibrium,

$$
r_{t}=q_{t} F_{1}\left(K_{t}, L_{t}\right)
$$

and

$$
w_{t}=q_{t} F_{2}\left(K_{t}, L_{t}\right)
$$

determine the factor prices, where we use the notational convention of $F_{1}(\cdot, \cdot)$ and $F_{2}(\cdot, \cdot)$ denoting partial derivatives with respect to the first and the second term.

\subsubsection{Intermediate goods producers}

Intermediate goods are made from specialized capital which is provided by the capital suppliers who are indexed by $j \in[0,1]$. The production function for the intermediate good $z$ is:

$$
y_{t}(z)=\left[\int_{0}^{1} X_{t}(j)^{\alpha} d j\right]^{1 / \alpha},
$$

\footnotetext{
${ }^{2}$ Since there is a representative consumer, it is not necessary to consider trading of shares.
} 
where $0<\alpha<1$ and $X(j)$ is the input from supplier $j$. Each supplier provides input $X(j)$ which is made of $x(i, j)$ specific investments, where $i \in[0,1]$ is a type of investment. The input $X(j)$ is produced from

$$
X_{t}(j)=\exp \left[\int_{0}^{1} \ln x_{t}(i, j) d i\right] .
$$

The specific investment is done by purchasing the same unit of raw materials, whose unit price is $q_{t}$. Thus, in order to invest $x_{t}$ units, the supplier has to pay $q_{t} x_{t}$.

\subsubsection{Final goods producers}

Final goods are assembled from the intermediate goods under perfect competition. There is a unit measure of intermediate goods, indexed by $z \in[0,1]$. The production function is

$$
Y_{t}=\left[\int_{0}^{1} y_{t}(z)^{\phi} d z\right]^{1 / \phi},
$$

where $y_{t}(z)$ is the quantity of intermediate good $z$. We assume that $0<\phi<1$. In equilibrium, the output is used for consumption, investment, and government spending;

$$
K_{t+1}-(1-\delta) K_{t}+C_{t}+T_{t}=Y_{t}
$$

The price of each intermediate good price is $p_{t}(z)$. Because of the constant returns to scale production and perfect competition, there is no profit in the final goods production and we can assume a representative producer.

\subsection{The economy with complete contracts}

For a benchmark, first consider the situation where the contact between the intermediate good producer and the suppliers can be fully specified. Further assume that the intermediate goods producers can offer a take-it-or-leave-it contract to the suppliers. Since the suppliers' outside option is zero, the intermediate goods producer can extract all surplus.

Then, from symmetry, the intermediate input producer can produce $y_{t}(z)$ units of output with the cost $q_{t} y_{t}(z)$. From the profit maximization in the final goods sector, the demand for intermediate good $z$ is

$$
y_{t}(z)=p_{t}(z)^{\frac{1}{\phi-1}} Y_{t} .
$$


Thus the profit-maximization problem for the intermediate-good producer $z$ is

$$
\max _{p_{t}(z)} \quad \pi_{t}(z) \equiv\left(p_{t}(z)-q_{t}\right) p_{t}(z)^{\frac{1}{\phi-1}} Y_{t}
$$

and the solution is

$$
p_{t}(z)=\frac{q_{t}}{\phi}
$$

Since the final good's price is assumed to be $1, p_{t}(z)=1$ and therefore $q_{t}=\phi$. The factor prices are determined by

$$
r_{t}=\phi F_{1}\left(K_{t}, L_{t}\right)
$$

and

$$
w_{t}=\phi F_{2}\left(K_{t}, L_{t}\right)
$$

The quantity of raw material produced is $F\left(K_{t}, L_{t}\right)$ and in equilibrium, this is equal to $x_{t}(i, j)=X_{t}(j)=y_{t}(z)=Y_{t}$. The total profit for the intermediate-good producers is $\int_{0}^{1} \pi(z) d z=(1-\phi) Y_{t}$. Since there is no profit for the suppliers, this is the total profit $\Pi_{t}$.

The representative consumer's Euler equation is

$$
u_{1}\left(C_{t+1}, 1-L_{t+1}\right)=\beta\left(1+r_{t+1}-\delta_{K}\right) u_{1}\left(C_{t}, 1-L_{t}\right),
$$

which can be rewritten as

$$
u_{1}\left(C_{t+1}, 1-L_{t+1}\right)=\beta\left(1+\phi F_{1}\left(K_{t+1}, L\right)-\delta_{K}\right) u_{1}\left(C_{t}, 1-L_{t}\right)
$$

Similarly, the first-order condition on labor supply is

$$
u_{2}\left(C_{t}, 1-L_{t}\right)=w_{t} u_{1}\left(C_{t}, 1-L_{t}\right),
$$

which implies that

$$
u_{2}\left(C_{t}, 1-L_{t}\right)=\phi F_{2}\left(K_{t}, L_{t}\right) u_{1}\left(C_{t}, 1-L_{t}\right)
$$

The resource constraint is

$$
K_{t+1}+C_{t}=\left(1-\delta_{K}\right) K_{t}+F\left(K_{t}, L_{t}\right)
$$

Here, we used that $T_{t}=0$ and $r_{t} K_{t}+w_{t} L_{t}+\Pi_{t}=F\left(K_{t}, L_{t}\right)$. 


\subsection{The static economy with incomplete contracts}

Now we turns to the economy with incomplete contracts. We first solve the within-period problem. As will become clear, the decisions of intermediate and final goods producers are static in nature. It will be shown that, within a period, all quantities and prices can be determined as a function of the capital, labor, and by the current contractual environment.

\subsubsection{The intermediate goods producer problem}

First, we tackle the problem of an intermediate goods producer. Suppose that the contract between the intermediate goods producers and the suppliers is incomplete. For product $z$, we assume that (for every supplier $j$ ) the contract is complete for the investments $0 \leq i \leq \mu(z)$ and incomplete for $\mu(z)<i \leq 1$. That is, for the first $\mu(z)$ investments, the level of investments $x(i, j)$ is contractible, but for the rest of the investments, $x(i, j)$ is determined by suppliers. The departure from Acemoglu, Antràs, and Helpman's (2007) framework is that we allow $\mu(z)$ to be heterogeneous across $z$. The heterogeneity in $\mu(z)$ reflects the heterogeneity in contract-specificity we measured in Section 2. In this Section, we take the mapping $\mu(z)$ as given. In Section 3.5, we endogenize the economy's institutions and hence the mapping $\mu(z)$.

Following Acemoglu, Antràs, and Helpman (2007), we adopt the following timing in the game between the intermediate goods producer and the supplier.

1. The intermediate goods producer $z$ offers a contract $\left[\left\{x_{c}(i, j)\right\}_{i=0}^{\mu(z)}, \tau(j)\right]$ for every $j \in$ $[0,1] . x_{c}(i, j)$ is the contractible investment level and $\tau(j)$ is the upfront payment to supplier $j$.

2. Suppliers decide whether to accept the contract.

3. For $0 \leq i \leq \mu(z)$, the suppliers invest $x(i, j)=x_{c}(i, j)$. For $\mu(z)<i \leq 1$, they decide $x(i, j)$.

4. The suppliers and the intermediate good producer bargain over the division of the revenue. 
5. Output is produced, sold, and the revenue is distributed following the bargaining agreement.

The symmetric subgame perfect equilibrium (SSPE) of this game can be defined and characterized in a similar manner as Acemoglu, Antràs, and Helpman (2007). Below, for simplicity, we suppress the dependence of variables in $t$ and $z$.

In order to solve for the SSPE, we will move backwards, starting from the bargaining stage. As in Acemoglu, Antràs, and Helpman (2007), we use Shapley value as the bargaining solution, among the suppliers and the intermediate good producer. Following the same steps as Acemoglu, Antràs, and Helpman (2007), we obtain that supplier $j$ receives

$$
s_{j}=(1-\gamma) Y^{1-\phi}\left(\frac{x_{n}(j)}{x_{n}}\right)^{(1-\mu) \phi} x_{c}^{\phi \mu} x_{n}^{\phi(1-\mu)}
$$

where $\gamma \equiv \alpha /(\alpha+\phi)$, when it makes $x_{n}(j)$ units of noncontractible investment, the other suppliers make $x_{n}$ units of noncontractible investment, and $x_{c}$ is the amount of contractible investment. ${ }^{3}$ The intermediate good producer receives

$$
s_{i}=\gamma Y^{1-\phi} x_{c}^{\phi \mu} x_{n}^{\phi(1-\mu)}
$$

Foreseeing the bargaining outcome, each supplier decides the noncontractible investment to maximize its profit. Thus, in a symmetric equilibrium,

$$
x_{n}=\arg \max _{x_{n}(j)}(1-\gamma) Y^{1-\phi}\left(\frac{x_{n}(j)}{x_{n}}\right)^{(1-\mu) \phi} x_{c}^{\phi \mu} x_{n}^{\phi(1-\mu)}-q(1-\mu) x_{n}(j) .
$$

Solving this problem, the optimal noncontractible investment by the supplier for given $x_{c}$ is

$$
x_{n}\left(x_{c}\right)=\left[\frac{\alpha(1-\gamma)}{q} x_{c}^{\mu \phi} Y^{1-\phi}\right]^{\frac{1}{1-\phi(1-\mu)}} .
$$

The intermediate goods producer solves the problem

$$
\max _{x_{c}, \tau} s_{i}-\tau
$$

subject to (3) and

$$
s_{j}+\tau \geq \mu q x_{c}+(1-\mu) q x_{n} .
$$

\footnotetext{
${ }^{3}$ Appendix B describes the derivation for completeness.
} 
Since (4) holds with equality, the problem can be rewritten, using (1) and (2), as $\left(x_{n}\left(x_{c}\right)\right.$ is the function (3))

$$
\max _{x_{c}} Y^{1-\phi}\left[x_{c}^{\mu} x_{n}\left(x_{c}\right)^{1-\mu}\right]^{\phi}-\mu q x_{c}-(1-\mu) q x_{n}\left(x_{c}\right) .
$$

The solution to this problem is

$$
x_{c}=Y q^{-\frac{1}{1-\phi}}[\alpha(1-\gamma)]^{\frac{\phi(1-\mu)}{1-\phi}} B(\mu)^{1-\phi(1-\mu)}
$$

where

$$
B(\mu) \equiv\left\{\frac{\phi}{1-\phi(1-\mu)}[1-(1-\mu) \alpha(1-\gamma)]\right\}^{\frac{1}{1-\phi}} .
$$

$x_{n}$ can be solved as

$$
x_{n}=Y q^{-\frac{1}{1-\phi}}[\alpha(1-\gamma)]^{\frac{1-\phi \mu}{1-\phi}} B(\mu)^{\mu \phi} .
$$

The output is

$$
y=x_{c}^{\mu} x_{n}^{1-\mu}=Y q^{-\frac{1}{1-\phi}} D(\mu)
$$

where

$$
D(\mu) \equiv[\alpha(1-\gamma)]^{\frac{1-\mu}{1-\phi}} B(\mu)^{\mu}
$$

\subsubsection{Cross-sectional properties of the equilibrium}

A notable property of the solution is that, up to the multiplicative factor $Y q^{-\frac{1}{1-\phi}}$, the intermediate good's producer's choice of inputs $x_{c}, x_{n}$ and output depend only on its own parameter $\mu$. Also, the firm's profit similarly depends on a function of its $\mu$ and on the multiplicative factor $Y q^{-\frac{\phi}{1-\phi}}$. This property allows us to derive some properties of the economy, independent of capital and labor.

\subsubsection{Property 1: The distribution of intermediate goods depends only on the distribution of $\mu$.}

The relative output of each intermediate good is given by

$$
\frac{y\left(\mu\left(z^{\prime}\right)\right)}{y(\mu(z))}=\frac{D\left(\mu\left(z^{\prime}\right)\right)}{D(\mu(z))} \text {. }
$$


Note that $D(\mu)$ only depends on $\mu$ and parameters. Therefore, as long as $\mu$ is invariant, this ratio is invariant. As we will see below, the aggregate output changes over time as $K_{t}$ changes, as in the standard neoclassical growth model. However, if the institutions (and hence the firms' enforceability $\mu$ ) do not change over time, the relative output will be constant. This is inconsistent with the empirical regularities presented in Section 2. Of course, this outcome is a consequence of the particular formulation we adopted here, but this shows that replicating the pattern in Section 2 along the growth path is not a trivial task.

\subsubsection{Property 2: Firms with better enforceability $\mu$ are larger and more profitable.}

The cross-sectional distribution of intermediate good producers have the following property.

Proposition 1 If $\mu(z)>\mu\left(z^{\prime}\right)$, then $y_{t}(\mu(z))>y_{t}\left(\mu\left(z^{\prime}\right)\right)$.

Proof. See Appendix D.

An intermediate firm $z$ with a larger value of $\mu(z)$ face less problems with imperfect contractability with the supplier. Proposition 1 shows that their output is larger.

\subsubsection{General equilibrium}

Finally, we turn to characterize the aggregate outcome. From (5),

$$
\left[\int_{0}^{1} y_{t}(\mu(z))^{\phi} d z\right]^{\frac{1}{\phi}}=Y_{t} q_{t}^{-\frac{1}{1-\phi}}\left[\int_{0}^{1} D(\mu(z))^{\phi} d z\right]^{\frac{1}{\phi}} .
$$

Since the left-hand side is equal to $Y_{t}$, the price of raw materials is given by

$$
q=\left[\int_{0}^{1} D(\mu(z))^{\phi} d z\right]^{\frac{1-\phi}{\phi}} .
$$

Notice that the price of raw materials depends only on the distribution of $\mu$. If institutions (and hence enforceability) are fixed, then $q$ will be stationary.

Next, we turn to aggregate output. The total demand for the raw materials is

$$
\int_{0}^{1}\left[\mu x_{c}(\mu(z))+(1-\mu) x_{n}(\mu(z))\right] d z=Y q^{-\frac{1}{1-\phi}} \int_{0}^{1} H(\mu(z)) d z
$$


where

$$
H(\mu) \equiv \mu[\alpha(1-\gamma)]^{\frac{\phi(1-\mu)}{1-\phi}} B(\mu)^{1-\phi(1-\mu)}+(1-\mu)[\alpha(1-\gamma)]^{\frac{1-\phi \mu}{1-\phi}} B(\mu)^{\mu \phi}
$$

Here, $H(\mu)$ is the normalized demand for inputs by firm with enforceability $\mu$.

Since the supply of the raw materials is $F\left(K_{t}, L_{t}\right)$, this implies (using (6))

$$
Y_{t}=\frac{\left[\int_{0}^{1} D(\mu(z))^{\phi} d z\right]^{\frac{1}{\phi}}}{\int_{0}^{1} H(\mu(z)) d z} F\left(K_{t}, L_{t}\right) .
$$

Let

$$
\Theta \equiv \frac{\left[\int_{0}^{1} D(\mu(z))^{\phi} d z\right]^{\frac{1}{\phi}}}{\int_{0}^{1} H(\mu(z)) d z} .
$$

$\Theta$ depends only on the distribution of $\mu$, and thus the existence of $\mu$ acts as the change in Hicks-neutral technology in this framework. The source of this change in efficiency is misallocation - the raw material (which is the only productive resources here) is not allocated optimally across different investments $\left(x_{c}\right.$ and $x_{n}$ are different) because of contractual incompleteness.

Proposition 2 If $\mu(z) \in(0,1)$ for a strictly positive measure of $z$, then $\Theta<1$.

Proof. See Appendix D.

Intuitively, there are two reasons for $\Theta$ being less than one. The first is unbalanced input for a given intermediate good $z$ whose $\mu(z) \in(0,1)$. When $\mu(z) \in(0,1)$, the contractible investment $x_{c}$ and noncontractible investment $x_{n}$ are different, since they are governed by different incentives. Since the cost-minimizing combination of investments is to make all investment equal, this unbalancedness of input leads to inefficiency in production. The second is unbalanced production across intermediate goods. If $\mu(z)$ for some $z$ is smaller than others, these intermediate goods are produced at different amount. This is another cause of inefficiency, since the final goods are produced most effectively with equal amount of intermediate goods. 


\subsection{The dynamic economy with incomplete contracts}

We have seen that, at each point in time, the production side of the economy has an equilibrium such that all the prices and all the quantities (up to a multiplicative factor $F(K, L)$ ) depend only on the distribution of enforceability $\mu$. The coefficient $\Theta$ sums up the effect of these distortions in production. However, enforceability problems affect the demand for labor and capital and therefore their prices. As a result, the supply of labor and the accumulation of capital can be distorted due to the incompleteness of the contracts.

Since $r_{t}=q F_{1}\left(K_{t}, L_{t}\right)$ and $w_{t}=q F_{2}\left(K_{t}, L_{t}\right)$, the optimal solution of the representative consumer's problem satisfies the following first order conditions:

$$
\begin{gathered}
u_{1}\left(C_{t}, 1-L_{t}\right)=\beta\left(1+q F_{1}\left(K_{t+1}, L_{t+1}\right)-\delta_{K}\right) u_{1}\left(C_{t+1}, 1-L_{t+1}\right), \\
u_{2}\left(C_{t}, 1-L_{t}\right)=q F_{2}\left(K_{t}, L_{t}\right) u_{1}\left(C_{t}, 1-L_{t}\right),
\end{gathered}
$$

where $q$ is given in (6). The resource constraint is

$$
K_{t+1}+C_{t}=(1-\delta) K_{t}+\Theta F\left(K_{t}, L_{t}\right)
$$

Note that the system of equations above nests several different possibilities. First, when $\Theta=1$ and $q=1$, the economy is Pareto efficient. This is the case, for example, when the contract is complete and $\phi=1$. Second, when $\phi<1$ and contracts are complete, $\Theta=1$ and $q=\phi<1$. In this case, even with complete contracts, there are distortions that are reflected to factor income. This is due to imperfect competition in the intermediate goods sector. Third, if the contractual enforcement is imperfect and $\phi<1, \Theta<1$ and $q<1$ hold, while their exact values depend on the whole distribution of enforceabilities $\mu(z)$. For the second and third cases, the allocation is not Pareto efficient.

In our model, both $\Theta$ and $q$ are influenced by the distribution of $\mu$ and therefore affected by the contractual incompleteness. A small value of $\Theta$ means that there is a large production inefficiency originating from the two misallocations we discussed in Section 3.3.3. A value of $q$ less than one means that the factor suppliers are not able to receive their marginal product. The effect of $\mu$ on $\Theta$ and $q$ can be distinctive. For example, take an extreme case where 
$\mu(z)=0$ for all $z$. In this case $\Theta=1$ holds, because for given $K$ and $L$, all factors are used in a balanced manner across tasks and products. Thus there are no misallocations that reduce $\Theta$. However, the value of $q=\alpha \phi /(\alpha+\phi)$ is lower than $\phi$ (the value of $q$ in the complete contract case) in this case, because the factor demand is affected by the incompleteness of the contract.

Note that for a given production inefficiency $\Theta$, there is a discrepancy between social and private returns for capital and labor. In particular, the social returns are proportional to $\Theta$ while the private returns are proportional to $q$. Therefore, the ratio $\Theta / q$ is a measure of factor supply distortions. When $\Theta / q=1$, there is no distortion. When contracts are complete, $\Theta / q=1 / \phi$, which is larger than one when $\phi<1$. The following proposition characterizes the behavior of $\Theta / q$.

Proposition 3 If $\mu(z) \in[0,1)$ for a strictly positive measure of $z$, then $\Theta / q>1 / \phi$. Let $\Theta(\mu)$ be the value of $\Theta$ in an economy where all firms have enforceability $\mu$. Define $q(\mu)$ similarly. Then $\Theta(\mu) / q(\mu)$ is a strictly decreasing function of $\mu$.

\section{Proof. See Appendix D.}

The first part of the proposition implies that when contract enforcement is imperfect, the gap between social and private returns is larger than the perfect enforcement case. In that sense, the imperfection in contract enforcement worsens the factor supply distortions. The second part of the proposition deals with a special case where all industries have the same $\mu$. In this case, we can obtain a sharper characterization: the gap between the social and private returns widens monotonically as $\mu$ becomes smaller. Thus, the factor supply is more distorted in the economy where contract enforcement is more difficult.

In order to gain further intuition, consider a special case. Let $F(K, L)=K^{\theta} L^{1-\theta}$ where $\theta \in(0,1)$, and $u(C, 1-L)=\left(C^{\eta}(1-L)^{1-\eta}\right)^{\sigma} /(1-\sigma)$ where $\eta \in(0,1), \sigma>0$, and $\sigma \neq 1$. From (7), in the steady state, the following holds:

$$
\frac{K}{L}=\left[\frac{\theta q}{1 / \beta-1+\delta_{K}}\right]^{\frac{1}{1-\theta}} .
$$


Recall that in the first best, $q=1$. When $q<1$, the capital-labor ratio is smaller than the first best level, because the return to capital is lower than the case of first best. Combining this with (8) and (9), we obtain the steady-state level of labor ${ }^{4}$

$$
L=\left[\frac{1-\eta}{\eta(1-\theta)}\left(\frac{\Theta}{q}-\frac{\theta \delta_{K}}{1 / \beta-1+\delta_{K}}\right)+1\right]^{-1}
$$

and therefore the steady-state level of capital stock is

$$
K=\left[\frac{\theta q}{1 / \beta-1+\delta_{K}}\right]^{\frac{1}{1-\theta}}\left[\frac{1-\eta}{\eta(1-\theta)}\left(\frac{\Theta}{q}-\frac{\theta \delta_{K}}{1 / \beta-1+\delta_{K}}\right)+1\right]^{-1}
$$

The level of $L$ is a function of $\Theta / q$ that we highlight in Proposition 3. In particular, a large value of $\Theta / q$, which is a result of small $\mu$ (low level of contract enforcement) in Proposition 3 , leads to a small value of $L$. For $K$, the level of $q$ has an effect in addition to $\Theta / q$. Note, once again, that these distortions on $K$ and $L$ are in addition to the production inefficiency (that is, $\Theta<1$ ) that we highlighted in Section 3.3.

The inefficiency due to the misallocation is closely related to the recently evolving literature on misallocation, such as Restuccia and Rogerson (2008) and Hsieh and Klenow (2009). The discrepancy between private and social returns due to incompleteness of contract echoes a traditional view of institutional inefficiencies. For example, North and Thomas (1973) argue "Growth will simply not occur unless the existing economic organization is efficient. ... Some mechanism must be devised to bring social and private rates of return to closer parity." The next Section describes how such a mechanism can evolve over time.

\subsection{Economy with incomplete contracts and evolving institutions}

As we have seen in the previous Section (in particular Section 3.3.2.1), the model with constant levels of contract enforcement cannot replicate the empirical pattern in Section 2. Thus we turn to a model where contracting environment improves: $\mu(z)$ becomes larger over time. In general, the changes in economic institutions have been considered as an important engine of economic development by many historians. North and Weingast (1989) discuss how the government was able to commit to growth-promoting economic rules, such

\footnotetext{
${ }^{4}$ See Appendix $\mathrm{C}$ for details of derivation.
} 
as secure property rights, following Glorious Revolution in 17th-Century England. They argue that this change lead to factors that became a foundation of England's long-term economic success, such as the development of private capital market. Acemoglu, Johnson, and Robinson (2005b) describe the growth of Western Europe from 1500 to 1850 and argue that its dynamics was strongly affected by the development of commercial-friendly economic institutions, such as secure private property rights, which in turn was influenced by the medieval political institutions and the growth of Atlantic trade.

In the context of our model, $\mu(z)$ reflects the quality of contracting institutions. There are several possibilities in modeling how it can be improved. For example, it is possible that private agents who benefit from better contract enforcement (for example, intermediate goods producers in our setting) spend their own resources in order to make the contracting environment better. ${ }^{5}$ Here, as a first step, we assume that the contracting institutions are determined by the government actions. North (1990) argues "there are immense scale economise in policing and enforcing agreements by a polity that acts as a third party and uses coercion to enforce agreements (p.58)." He also notes that "creating a system of effective enforcement and of moral constraints on behavior is a long, slow process (p.60)." Acemoglu, Johnson and Robinson (2005a) argue that "if the legal system functions properly, there is an array of enforceable contracts ... These contracts can be enforced because there is an authority, a third party, with the power to enforce contracts. ... all such power emanates from state (p.429)." North and Thomas (1973) summarizes: "Justice and the enforcement of property rights are simply another example of a public good publicly funded (p.7)." Thus the natural first attempt would be to model this process as government investment in a type of "social capital" that enhances contract enforcement. ${ }^{6}$ One example that fits this formulation is an

\footnotetext{
${ }^{5}$ Popov (2014) considers a related principal-agent model where principal chooses the level of enforcement.

${ }^{6}$ We use the term "social capital" in an analogy to physical capital stock, as is clear in our formulation. North (1981, Chapter 15) is explicit about the analogy to capital stock in describing the incremental nature of institutional change. Some other researchers use the term "social capital" with somewhat different connotation - for example, Knack and Keefer (1997) consider "trust" and "civic norms" as the contents of social capital. Hall and Jones (1999) consider a concept similar to our social capital and they call it "social infrastructure." They use an index of government antidiversion policy, originally used by Knack and Keefer (1995), and openness to trade in constructing their social infrastructure measure. They argue that social infrastructure is essential in explaining cross-country income differences. Acemoglu, Johnson, and Robinson
} 
improvement of legal system and courts, which is an important part of contract enforcement institutions.

\subsubsection{General formulation}

Let the level of social capital at time $t$ be $G_{t}$. The social capital evolves with

$$
G_{t+1}=\left(1-\delta_{G}\right) G_{t}+I_{G}
$$

where $\delta_{G}$ is the depreciation rate of the social capital and $I_{G}$ is the investment (government spending). We assume that institutional investment is in the form of final goods.

We model the effect of institutions on firms' contractibility $\mu(z)$ in a manner that is consistent with Nunn's (2007) measure of contract intensity. We assume that a fraction $\underline{\mu}(z)$ of investments in inputs are of standardized nature and can be bought on an exchange; as a result these investments are not subject to hold-up problems. This innate enforceability follows from the nature of the production process and is assumed to be constant over time. We assume that $\underline{\mu}(z)$ can be different across different $z$ and is continuous and strictly increasing (the firms are indexed in order of innate enforceability) function of $z$.

The intermediate good firm uses the public enforcement to ensure contract compliance on the remaining $1-\underline{\mu}(z)$ types of investment. The probability of success depends on the level of social capital $G_{t}$. The total fraction of enforceable investment $\mu\left(z, G_{t}\right)$ is expressed as

$$
\mu\left(z, G_{t}\right)=\underline{\mu}(z)+h\left(G_{t}\right)[1-\underline{\mu}(z)]
$$

where the function $h\left(G_{t}\right)$ is the probability of successful enforcement. We assume that $h(\cdot)$ is differentiable, strictly increasing, strictly concave and $0=h(0)<h(G)<1$ for any $G>0$.

Thus in our model, institutions (represented by $G_{t}$ ) affect economic outcomes by changing the enforceability characteristics of firms $\mu\left(z, G_{t}\right)$. As a result, institutions determine the distribution of $\mu$ and hence the economy's productivity $\Theta$. In the following, (with a slight

(2001) and Rodrik, Subramanian, and Trebbi (2004) also find that measures of property rights and rule of law are important in explaining cross-country income differences using different empirical strategies. La Porta et al. (1999) analyze the determinant of government quality, which includes the index of property rights, corruption, and bureaucratic delays, in the cross section of countries. 
abuse of notation) we denote this dependence as $\Theta\left(G_{t}\right)$. Similarly, the price of raw materials is also a function of $G_{t}$ and expressed as $q\left(G_{t}\right)$.

With these expressions, the aggregate resource constraint for the economy is given by

$$
C_{t}+G_{t+1}+K_{t+1}=\Theta\left(G_{t}\right) F\left(K_{t}, L_{t}\right)+\left(1-\delta_{K}\right) K_{t}+\left(1-\delta_{G}\right) G_{t}
$$

Here, we have used the assumption that institutional investment is in terms of the final good. We assume that the government (whose function is to undertake institutional investment) has access to lump-sum taxes, or equivalently, can tax firm profits. We also impose the following constraints on $C_{t}, K_{t+1}$, and $L_{t}$ :

$$
\begin{gathered}
C_{t}>0, \\
K_{t+1}>0,
\end{gathered}
$$

and

$$
L_{t} \in(0,1)
$$

for all $t$. These ensure that the solutions are interior and can be characterized by the firstorder conditions.

Since labor supply and investment in the capital stock $K_{t+1}$ must be consistent with household optimality, the allocation must satisfy

$$
u_{1}\left(C_{t}, 1-L_{t}\right)=\beta\left(1+q\left(G_{t+1}\right) F_{1}\left(K_{t+1}, L_{t+1}\right)-\delta_{K}\right) u_{1}\left(C_{t+1}, 1-L_{t+1}\right)
$$

and

$$
u_{2}\left(C_{t}, 1-L_{t}\right)=q\left(G_{t}\right) F_{2}\left(K_{t}, L_{t}\right) u_{1}\left(C_{t}, 1-L_{t}\right)
$$

Then the benevolent government's problem is given by

$$
\max _{\left\{C_{t}, K_{t+1}, G_{t+1}\right\}} \sum_{t=0}^{\infty} \beta^{t} u\left(C_{t}, 1-L_{t}\right)
$$

subject to (11), (12), (13), (14), (15), and (16).

The problem above is similar in nature to the classic problem of finding optimal distortionary taxation. We can transform the problem into a recursive form using the technique 
pioneered by Kydland and Prescott (1980). In particular, we introduce an additional state variable $\lambda$ which is the right-hand side equation (15). The problem becomes:

$$
v(K, G, \lambda)=\sup _{C>0, L \in(0,1), K^{\prime}>0, G^{\prime} \geq 0, \lambda^{\prime}} u(C, 1-L)+\beta v\left(K^{\prime}, G^{\prime}, \lambda^{\prime}\right)
$$

subject to

$$
\begin{gathered}
C+K^{\prime}+G^{\prime}=\Theta(G) F(K, L)+\left(1-\delta_{K}\right) K+\left(1-\delta_{G}\right) G, \\
q(G) F_{2}(K, L) u_{1}(C, 1-L)=u_{2}(C, 1-L), \\
u_{1}(C, 1-L)=\lambda^{\prime}, \\
\beta\left[1-\delta_{K}+q(G) F_{1}(K, L)\right] u_{1}(C, 1-L)=\lambda,
\end{gathered}
$$

and

$$
\lambda^{\prime} \in \Omega\left(K^{\prime}, G^{\prime}\right)
$$

Here, prime (') represents the variable in the next period. The equation (17) is the resource constraint, (18) is the individual optimality condition for labor supply, (19) is the version of the consumer's Euler equation and (20) is a promise-keeping constraint on $\lambda$. Finally, (21) is a condition that $\lambda^{\prime}$ falls into the set of next period's Lagrangian multipliers which can be attained for $\left(K^{\prime}, G^{\prime}\right)$. This is also known as an "admissibility condition" and $\Omega(K, G)$ is called the "admissible set." The definition and the computation of $\Omega(K, G)$ will be spelled out in the special case described below.

\subsubsection{Special case with fixed labor supply}

The problem can be substantially simplified by abstracting from the labor-leisure choice and fixing the amount of labor supply. We consider this special case in this Section. We denote the utility function as $u\left(C_{t}\right)$ and normalize $L_{t}$ to 1 . To simplify notation, let $f(K) \equiv F(K, 1)$. Now the condition (18) can be dropped from the recursive problem. In this case, given the state variables, the promise-keeping condition (20) pins down $C$ uniquely by

$$
C=u^{\prime-1}\left[\frac{\lambda}{\beta\left(1-\delta_{K}+q(G) f^{\prime}(K)\right)}\right]
$$


Similarly (19) and (20) imply

$$
\lambda^{\prime}=\frac{\lambda}{\beta\left(1-\delta_{K}+q(G) f^{\prime}(K)\right)} .
$$

Then the planner's problem is reduced to the choice of $\left(K^{\prime}, G^{\prime}\right)$ subject to the resource and admissibility constraints.

Before solving the problem, we have to pin down the admissible set $\Omega\left(K^{\prime}, G^{\prime}\right)$. Let $\Delta \equiv\left\{\left\{x_{t}\right\}_{t=0}^{\infty}, x_{t} \in \mathbf{R}_{+}^{3}\right\}$ be the space of sequences of nonnegative triplets of real numbers. Let $\Gamma: \mathbf{R}_{++} \times \mathbf{R}_{+} \rightrightarrows \Delta$ be the correspondence that maps from the pair $(K, G)$ into the set of all sequences that satisfy (11), (12), (13), (14), and (15), where the first component of the triplet is understood as $C$, the second is $K^{\prime}$, and the third is $G^{\prime}$.

Define the mapping $m: \Delta \times \mathbf{R}_{++} \times \mathbf{R}_{+} \rightarrow \mathbf{R}$ by

$$
m\left(\left(x_{t}\right), K, G\right) \equiv \beta\left(1-\delta_{k}+q(G) f^{\prime}(K)\right) u^{\prime}\left(x_{0}(1)\right)
$$

where $\left(x_{t}\right)$ is an element of $\Delta$ and $x_{0}(1)$ represents the first component of $x_{0}$ (that is, the consumption at time 0 ). Then the admissible set is formally given by

$$
\Omega(K, G)=\left\{m\left(\left(x_{t}\right), K, G\right):\left(x_{t}\right) \in \Gamma(K, G)\right\} .
$$

The following proposition shows that $\Omega(K, G)$ can be characterized by its lower bound.

Proposition 4 For every $(K, G) \in \mathbf{R}_{++} \times \mathbf{R}_{+}, \Omega(K, G)=[\omega(K, G), \infty)$, where $\omega$ is a continuous function which is strictly decreasing in $K$.

Proposition 4 implies that $\Omega(K, G)$ is convex-valued and closed. The admissibility set $\Omega(K, G)$ has an obvious recursive structure: for a given admissible triplets $\left(\lambda^{\prime}, K^{\prime}, G^{\prime}\right)$ that satisfies (21), the constraints (17), (19), and (20) provide restrictions on all combinations of $(\lambda, K, G)$ that makes $\left(\lambda^{\prime}, K^{\prime}, G^{\prime}\right)$ feasible. In turn, these combinations of $(\lambda, K, G)$ have to be consistent with the admissible set of $\left(\lambda^{\prime}, K^{\prime}, G^{\prime}\right)$ postulated initially. ${ }^{7}$

\footnotetext{
${ }^{7}$ This idea was first demonstrated by Kydland and Prescott (1980) and later formalized by Abreu, Pearce and Stacchetti (1990).
} 
The special structure of our problem allows us to find $\Omega$ by an iterative procedure. Let $\mathbf{v}: \mathbf{R}_{++} \times \mathbf{R}_{+} \rightarrow \mathbf{R}_{+}$be a continuous function. This is the (initial) guess for $\omega$. Define the operator $\mathbf{T}$ by:

$$
\operatorname{Tv}(K, G)=\min _{C>0, K^{\prime}>0, G^{\prime} \geq 0, \lambda^{\prime}} \lambda=\beta\left(1-\delta_{K}+q(G) f^{\prime}(K)\right) u^{\prime}(C)
$$

subject to

$$
\begin{gathered}
C+K^{\prime}+G^{\prime}=\Theta(G) f(K)+\left(1-\delta_{K}\right) K+\left(1-\delta_{G}\right) G, \\
u^{\prime}(C)=\lambda^{\prime},
\end{gathered}
$$

and

$$
\lambda^{\prime} \geq \mathbf{v}\left(K^{\prime}, G^{\prime}\right)
$$

This problem is well-defined for a particular subset of functions, as is shown below.

Lemma 1 Let $\mathcal{A} \equiv\left\{\mathbf{v}: \mathbf{R}_{++} \times \mathbf{R}_{+} \rightarrow \mathbf{R}_{++}, \mathbf{v}\right.$ is continuous and $\left.\lim _{K \rightarrow 0} \mathbf{v}(K, G)=\infty, \forall G\right\}$. Then $\mathbf{T}$ is defined on $\mathcal{A}$ and $\mathbf{T} \mathcal{A} \subseteq \mathcal{A}$.

Proof. See Appendix D.

Then one systematic method of finding $\omega$ turns out to be to start with some $\mathbf{v} \leq \omega$ and iterate on the operator $\mathbf{T}$ till convergence.

Lemma 2 Let $\mathbf{v} \in \mathcal{A}, \mathbf{v} \leq \omega$, and $\mathbf{T} \mathbf{v} \geq \mathbf{v}$. Then for every $(K, G)$, the sequence $\left(\mathbf{T}^{n} \mathbf{v}\right)(K, G)$ converges and $\lim _{n \rightarrow \infty}\left(\mathbf{T}^{n} \mathbf{v}\right)(K, G)=\omega(K, G)$.

Proof. See Appendix D.

One initial guess that satisfies the conditions of Lemma 1 and Lemma 2 (with Inada-like conditions on $f(K))$ is

$$
\mathbf{v}(K, G)=\beta\left(1-\delta_{K}+q(G) f^{\prime}(K)\right) u^{\prime}\left(\Theta(G) f(K)+\left(1-\delta_{K}\right) K+\left(1-\delta_{G}\right) G\right) .
$$

This gives the upper bound consumption $C$ to the consumer at the current period $\left(K^{\prime}=0\right.$ and $G^{\prime}=0$ ), which is unattainable because of the constraint $K^{\prime}>0$, and therefore $\mathbf{v} \leq \omega$ and $\mathbf{T} \mathbf{v} \geq \mathbf{v}$ are satisfied. 


\subsubsection{Numerical implementation}

[In progress]

\section{Conclusion}

[To be written] 


\section{References}

[1] Abreu, Dilip; David Pearce; and Ennio Stacchetti (1990). "Toward a Theory of Discounted Repeated Games with Imperfect Monitoring," Econometrica 58, 1041-1063

[2] Acemoglu, Daron; Pol Antràs; and Elhanan Helpman (2007). "Contracts and Technology Adoption," American Economic Revew 97, 916-943.

[3] Acemoglu, Daron; Simon Johnson; and James A. Robinson (2001). "The Colonial Origins of Comparative Development: An Empirital Investigation," American Economic Review 91, 1369-1401.

[4] Acemoglu, Daron; Simon Johnson; and James A. Robinson (2005a). "Institutions as a Fundamental Cause of Long-Run Growth," in Philippe Aghion and Steven Durlauf (eds.) Handbook of Economic Growth, Volume 1A, Amsterdam: North-Holland.

[5] Acemoglu, Daron; Simon Johnson; and James A. Robinson (2005b). "The Rise of Europe: Atlantic Trade, Institutional Change, and Economic Growth," American Economic Review 95, 546-579.

[6] De Soto, Hernando (1989). The Other Path, New York: Basic Books.

[7] De Soto, Hernando (2000). The Mystery of Capital, New York: Basic Books.

[8] Djankov, Simeon; Rafael La Porta; Florencio Lopez-de-Silanes; and Andrei Shleifer (2002). "The Regulation of Entry," Quarterly Journal of Economics 117, 1-37.

[9] Djankov, Simeon; Rafael La Porta; Florencio Lopez-de-Silanes; and Andrei Shleifer (2003). "Courts," Quarterly Journal of Economics 118, 453-517.

[10] Hall, Robert E. and Charles I. Jones (1999). "Why Do Some Countries Produce So Much More Output per Worker than Others?" Quarterly Journal of Economics 114, 83-116.

[11] Helpman, Elhanan (2004). The Mystery of Economic Growth, Cambridge: Harvard University Press. 
[12] Hsieh, Chang-Tai and Peter J. Klenow (2009). "Misallocation and Manufacturing in China and India," Quarterly Journal of Economics 124, 1403-1448.

[13] Knack, Stephen and Philip Keefer (1995). "Institutions and Economic Performance: Cross-country Tests Using Alternative Institutional Measuers," Economics and Politics $7,207-227$.

[14] Knack, Stephen and Philip Keefer (1997). "Does Social Capital Have an Economic Payoff? A Cross-Country Investigation," Quarterly Journal of Economics 112, 1251-1288.

[15] Kydland, Finn and Edward S. Prescott (1980). "Dynamic Optimal Taxation, Rational Expectation and Optimal Control," Journal of Economic Dynamics and Control 2, 7991.

[16] La Porta, Rafael; Florencio Lopez-de-Silanes; Andrei Shleifer; and Robert Bishny (1999). "The Quality of Government," Journal of Law, Economics, and Organization 15, 222289.

[17] North, Douglass C. (1981). Structure and Change in Economic History, New York: Norton.

[18] North, Douglass C. (1990). Institutions, Institutional Change and Economic Performance, Cambridge: Cambridge University Press.

[19] North, Douglass C. and Robert P. Thomas (1973). The Rise of the Western World: A New Economic History, Cambridge: Cambridge University Press.

[20] North, Douglass C. and Barry R. Weingast (1989). "Constitutions and Commitment: The Evolution of Institutional Governing Public Choice in Seventeenth-Century England," Journal of Economic History 49, 803-832.

[21] Nunn, Nathan (2007). "Relationship-Specificity, Incomplete Contracts, and the Pattern of Trade," Quarterly Journal of Economics 122, 569-600. 
[22] Popov, Latchezar (2014). "Enforcement Frictions and Optimal Lending Contracts," Economic Theory 57, 195-222.

[23] Restuccia, Diego and Richard Rogerson (2008). "Policy Distortions and Aggregate Productivity with Heterogeneous Plants," Review of Economic Dynamics 11, 707-720.

[24] Rodrik, Danil Arvind Subramanian; and Francesco Trebbi (2004). "Institutions Rule: The Primacy of Institutions Over Geography and Integration in Economic Development," Journal of Economic Growth 9, 131-165. 


\section{Appendix}

\section{A Details on data sources}

We use the measure of contract intensity developed by Nunn (2007). That measure is based on data from the input-output tables of the U.S. for 1997. Nunn (2007) assigns a contract intensity score to 386 out of 486 categories in the 1997 IO classification. Since the missing categories are from service industries, we focus the analysis on manufacturing (where the data is complete). Another reason we use manufacturing sector is that we want to stay away from the issue of structural transformation, which can be driven by the demand side.

We use data on production from the KLEMS initiative. KLEMS uses ISIC 3.1. industry classification at the two digit level (60 industries). We employ the following procedure to assign a contract intensity measure on each of these industries. The BEA provides a concordance between 1997 IO and the 1997 version of the North American Industry Classification System (NAICS). The Census provides a concordance between 2002 version of NAICS and ISIC 3.1. Finally, we use concordance between the 1997 and 2002 versions of NAICS, provided by the BEA.

Many IO codes are mapped onto multiple ISIC 3.1 categories. For category $i$ at the two-digit ISIC 3.1 classification, we assign the following contract intensity measure:

$$
\hat{z}_{i}=\frac{\sum_{j} x_{i, j} z_{j}}{\sum_{j} x_{i, j}},
$$

where $j$ spans the 1997 IO categories, $x_{i, j}$ is the number of NAICS codes that are mapped to both $i$ category in ISIC and $j$ category in the IO classification; $z_{j}$ is the contract intensity measure of Nunn (2007).

For a few countries, some of the 60 ISIC 3.1 categories are aggregated. In this case, we compute a weighted average of the scores of constituent categories and use it as a measure. We use the average share of each industry in the grouping in the UK as weights. 


\section{B Derivation of the Shapley value}

We follow the "heuristic derivation" of Acemoglu, Antràs and Helpman (2007). To compute the Shapley value, we first consider all feasible permutations of all players. Then consider the marginal contribution of a particular player to the coalition ordered below her. The Shapley value is the average of these marginal contributions.

Now, consider the marginal contribution of a particular supplier. The price of intermediate $\operatorname{good} z$ is

$$
p(z)=Y^{1-\phi} y(z)^{\phi-1},
$$

and thus the revenue is

$$
R(z)=Y^{1-\phi} y(z)^{\phi}
$$

Using the production function, the revenue generated by the coalition of the intermediate good firm and $n$ suppliers $(n \in[0,1])$ is

$$
R_{n}=Y^{1-\phi}\left[\int_{0}^{n}\left(\exp \left(\int_{0}^{1} \ln x(i, j) d i\right)\right)^{\alpha} d j\right]^{\phi / \alpha}
$$

The marginal contribution, evaluated with $x(i, j)=x_{c}$ for $i \in[0, \mu]$ and $j \in[0, n], x(i, j)=x_{n}$ for $i \in(\mu, 1]$ and $j \in[0, n)$, and $x(i, j)=x_{n}(j)$ for $i \in(\mu, 1]$ and $j=n$ is

$$
m(j, n) \equiv \frac{\partial R_{n}}{\partial n}=\frac{\phi}{\alpha} Y^{1-\phi}\left[\frac{x_{n}(j)}{x_{n}}\right]^{(1-\mu) \phi} x_{c}^{\phi \mu} x_{n}^{\phi(1-\mu)} n^{(\phi-\alpha) / \alpha} .
$$

The marginal contribution of supplier $j$ is zero if the intermediate good firm is not included in the coalition. Thus the marginal contribution is $m(j, n)$ with probability $n$ and zero with probability $1-n$. Considering all possible orderings, the Shapley value for supplier $j$ is

$$
s_{j}=\int_{0}^{1} n m(j, n) d n=(1-\gamma) Y^{1-\phi}\left[\frac{x_{n}(j)}{x_{n}}\right]^{(1-\mu) \phi} x_{c}^{\phi \mu} x_{n}^{\phi(1-\mu)} .
$$

The intermediate firm receives the leftover of the revenue in the symmetric equilibrium:

$$
s_{i}=\gamma Y^{1-\phi} x_{c}^{\phi \mu} x_{n}^{\phi(1-\mu)}
$$




\section{Derivation of the steady state expressions in Section 3.4}

The first-order conditions at any date are:

$$
\begin{gathered}
\frac{w_{t}}{c_{t}}=\frac{(1-\eta) / \eta}{1-L_{t}} \\
c_{t}^{\eta(1-\sigma)-1}\left(1-L_{t}\right)^{(1-\eta)(1-\sigma)}=\beta\left(1-\delta_{K}+r_{t+1}\right) c_{t+1}^{\eta(1-\sigma)-1}\left(1-L_{t+1}\right)^{(1-\eta)(1-\sigma)}
\end{gathered}
$$

Consider the steady state values and omit the time subscripts. Then,

$$
\frac{w}{Y-\delta_{K} K}=\frac{(1-\eta) / \eta}{1-L}
$$

and

$$
r=\frac{1}{\beta}-1+\delta_{K}
$$

hold.

Let $X=K^{\theta} L^{1-\theta}$ be the steady-state production of raw materials. Final output is $Y=\Theta X$. Then the steady state factor prices are:

$$
w=\frac{(1-\theta) X}{L} q
$$

and

$$
r=\frac{\theta X}{K} q
$$

Plugging $r$ in (23), we obtain

$$
\frac{X}{K}=\frac{m}{q},
$$

where $m=\left(1 / \beta-1+\delta_{K}\right) / \theta$ and $m$ is independent of the distribution of $\mu$.

Using the expression for $w$, we rewrite (22) as

$$
\frac{\frac{(1-\theta) X}{L} q}{\Theta X-\delta_{k} K}=\frac{(1-\eta) / \eta}{1-n}
$$

or

$$
\frac{\frac{(1-\theta) X}{K} q \frac{1}{L}}{\Theta \frac{X}{K}-\delta_{K}}=\frac{(1-\eta) / \eta}{1-L}
$$

Using (25),

$$
\frac{\frac{(1-\theta) m}{q} q \frac{1}{L}}{\Theta \frac{m}{q}-\delta_{K}}=\frac{(1-\eta) / \eta}{1-L} .
$$


Then solving for $L$, and substituting $m$ back, we obtain

$$
L=\left[\frac{1-\eta}{\eta(1-\theta)}\left(\frac{\Theta}{q}-\frac{\delta_{K} \theta}{1 / \beta-1+\delta_{k}}\right)+1\right]^{-1}
$$

the expression in the main text. The expression of $K / L$ can easily be derived from (23) and (24).

\section{Proofs}

Proof of Proposition 1. It is sufficient to show that $D(\mu)$ is strictly increasing. From the expression in the main body of the paper,

$$
D(\mu)=[\alpha(1-\gamma)]^{\frac{1-\mu}{1-\phi}} B(\mu)^{\mu} .
$$

Define $p \equiv \alpha(1-\gamma)$. Note that $p=\alpha \phi /(\alpha+\phi)<\phi$. Then we have

$$
D(\mu)=p^{\frac{1}{1-\phi}}\left(\frac{B(\mu)}{p^{1 /(1-\phi)}}\right)^{\mu}
$$

Substitute the expression for $B(\mu)$ to get

$$
\begin{gathered}
D(\mu)=p^{\frac{1}{1-\phi}}\left(\frac{\phi}{p} \frac{1-p+p \mu}{1-\phi+\phi \mu}\right)^{\frac{\mu}{1-\phi}} \equiv p^{\frac{1}{1-\phi}} f(\mu)^{\frac{\mu}{1-\phi}} \\
D^{\prime}(\mu)=p^{\frac{1}{1-\phi}}\left[\frac{\mu}{1-\phi} f(\mu)^{\frac{\mu}{1-\phi}-1} f^{\prime}(\mu)+f(\mu)^{\frac{\mu}{1-\phi}} \frac{1}{1-\phi} \ln (f(\mu))\right] \\
=\frac{1}{1-\phi} p^{\frac{1}{1-\phi}} f(\mu)^{\frac{\mu}{1-\phi}}\left[\mu \frac{f^{\prime}(\mu)}{f(\mu)}+\ln (f(\mu))\right]
\end{gathered}
$$

Let $g(\mu) \equiv \mu f^{\prime}(\mu) / f(\mu)+\ln (f(\mu))$. Then $D^{\prime}(\mu)>0$ is equivalent to $g(\mu)>0$. We will show that $g^{\prime}(\mu)<0$ and $g(1)>0$. First, we take derivatives to see that

$$
\begin{aligned}
g^{\prime}(\mu) & =\frac{p-\phi}{(1-p+p \mu)(1-\phi+\phi \mu)}[(1-p+p \mu)(1-\phi+\phi \mu)-\mu \phi(1-p+p \mu)-\mu p(1-\phi+\phi \mu)+1] \\
& =\frac{p-\phi}{(1-p+p \mu)(1-\phi+\phi \mu)}[(1-\phi)(1-p+p \mu)+1-\mu p(1-\phi+\phi \mu)]<0,
\end{aligned}
$$

where the last inequality follows from the fact that $p<\phi$ and all the other terms are positive.

Finally $g(1)=\ln (\phi)-\ln (p)+p-\phi$. Since $\phi>p$ and $\ln$ is strictly concave, $\ln (\phi)>$ $\ln (p)+\frac{1}{\phi}(\phi-p)$. Then $g(1)>\left(\frac{1}{\phi}-1\right)(\phi-p)>0$. 


\section{Proof of Proposition 2.}

Define

$$
\eta(\mu) \equiv \frac{\mu x_{c}(\mu)+(1-\mu) x_{n}(\mu)}{y(\mu)} .
$$

(Here, we are explicit about the dependence of $x_{c}, x_{n}$, and $y$ on $\mu$.) From the production function (5),

$$
\eta(\mu)=\frac{\mu+(1-\mu) x_{n}(\mu) / x_{c}(\mu)}{\left(x_{n}(\mu) / x_{c}(\mu)\right)^{1-\mu}} .
$$

It is straightforward to show that $\eta(\mu)>1$ when $x_{n}(\mu) / x_{c}(\mu) \neq 1$.

From the expressions on $x_{n}(\mu)$ and $x_{c}(\mu)$ in the main text,

$$
x_{n}(\mu) / x_{c}(\mu)=\alpha(1-\gamma) B(\mu)^{-(1-\phi)} .
$$

Substituting the expression for $B(\mu)$ in the main text, we can see that

$$
\frac{d}{d \mu} \frac{x_{n}(\mu)}{x_{c}(\mu)}=\frac{\alpha(1-\gamma)}{\phi} \frac{\phi-\alpha(1-\gamma)}{(1-(1-\mu) \alpha(1-\gamma))^{2}}>0 .
$$

Then for all $\mu<1, x_{n}(\mu) / x_{c}(\mu)<x_{n}(1) / x_{c}(1)=\alpha /(\alpha+\phi)<1$. Therefore $\eta(\mu)>1$ for any $\mu<1$.

Since the market for raw materials clears in equilibrium,

$$
\begin{aligned}
F(K, L) & =\int_{0}^{1}\left[\mu(z) x_{c}(\mu(z))+(1-\mu(z)) x_{n}(\mu(z))\right] d z \\
& =\int_{0}^{1} \eta(\mu(z)) y(\mu(z)) d z \\
& >\int_{0}^{1} y(\mu(z)) d z \\
& =\left[\int_{0}^{1} y(\mu(z)) d z\right]^{\frac{\phi}{\phi}} \\
& \geq\left[\int_{0}^{1} y(\mu(z))^{\phi} d z\right]^{\frac{1}{\phi}}=Y,
\end{aligned}
$$

where the third line follows from the fact that $y(\mu(z))>0$ for all $z$ and $\eta(\mu(z))>1$ for a positive measure of $z$. The fifth line follows from Jensen's inequality. Thus, the chain of inequalities implies $Y<F(K, L)$, therefore $\Theta<1$.

\section{Proof of Proposition 3.}


We show the second statement first. From the derivation in the main text, we know that

$$
\frac{\Theta}{q}=\frac{\frac{\left[\int_{0}^{1} D(\mu(z))^{\phi} d z\right]^{\frac{1}{\phi}}}{\int_{0}^{1} H(\mu(z)) d z}}{\left[\int_{0}^{1} D(\mu(z))^{\phi} d z\right]^{\frac{1-\phi}{\phi}}}=\frac{\int_{0}^{1} D(\mu(z))^{\phi} d z}{\int_{0}^{1} H(\mu(z)) d z} .
$$

Then in the case when all intermediate goods producers have the same $\mu$, we get:

$$
\frac{\Theta(\mu)}{q(\mu)}=\frac{D(\mu)^{\phi}}{H(\mu)}=D(\mu)^{\phi-1} \frac{D(\mu)}{H(\mu)} .
$$

From the derivation in the main text,

$$
D(\mu)^{\phi-1}=[\alpha(1-\gamma)]^{-(1-\mu)} B(\mu)^{-\mu(1-\phi)}=p^{-(1-\mu)} B(\mu)^{-\mu(1-\phi)},
$$

where we defined $p \equiv \alpha(1-\gamma)=\alpha \phi /(\alpha+\phi)$. Note that $p \in(0,1)$.

From the definitions of $H$ and $D$, it follows that

$$
\frac{D(\mu)}{H(\mu)}=\frac{p^{1-\mu} B(\mu)^{-(1-\mu)(1-\phi)}}{\mu+(1-\mu) p B(\mu)^{-(1-\phi)}}
$$

Combining the two expressions above,

$$
\frac{\Theta(\mu)}{q(\mu)}=\frac{p^{-(1-\mu)} B(\mu)^{-\mu(1-\phi)} p^{1-\mu} B(\mu)^{-(1-\mu)(1-\phi)}}{\mu+(1-\mu) p B(\mu)^{-(1-\phi)}}=\frac{B(\mu)^{-(1-\phi)}}{\mu+(1-\mu) p B(\mu)^{-(1-\phi)}} \equiv \frac{f(\mu)}{g(\mu)},
$$

where $f$ and $g$ represent the numerator and denominator respectively. Since

$$
\frac{d}{d \mu} \frac{\Theta(\mu)}{q(\mu)}=\frac{1}{f(\mu) g(\mu)}\left[\frac{f^{\prime}(\mu)}{f(\mu)}-\frac{g^{\prime}(\mu)}{g(\mu)}\right]
$$

it is clearly sufficient to show that $\frac{f^{\prime}(\mu)}{f(\mu)}-\frac{g^{\prime}(\mu)}{g(\mu)}<0$ for all $\mu$.

First, we derive $f^{\prime} / f$. Substituting the expression for $B(\mu)$, we get that

$$
f(\mu)=B(\mu)^{-(1-\phi)}=\frac{1-\phi+\phi \mu}{\phi[1-p+p \mu]} .
$$

Taking derivatives, we see that:

$$
\frac{f^{\prime}(\mu)}{f(\mu)}=\frac{\phi-p}{(1-p+p \mu)(1-\phi+\phi \mu)}
$$

Next, we turn to $g^{\prime} / g$. Again, we substitute the expression for $B(\mu)$ to show that

$$
g(\mu)=\mu+(1-\mu) \frac{p}{\phi} \frac{1-\phi+\phi \mu}{1-p+p \mu}
$$


Taking derivatives yields,

$$
\frac{g^{\prime}(\mu)}{g(\mu)}=\frac{1-\frac{p}{\phi} \frac{1-\phi+\phi \mu}{1-p+p \mu}+(1-\mu) \frac{p}{\phi} \frac{\phi-p}{(1-p+p \mu)^{2}}}{\mu+(1-\mu) \frac{p}{\phi} \frac{1-\phi+\phi \mu}{1-p+p \mu}} .
$$

Simplifying,

$$
\frac{g^{\prime}(\mu)}{g(\mu)}=\frac{1}{1-p+p \mu} \frac{\phi-p}{\mu(\phi-p+p \phi)+p-p \phi} .
$$

This implies that

$$
\begin{aligned}
\frac{f^{\prime}(\mu)}{f(\mu)}-\frac{g^{\prime}(\mu)}{g(\mu)} & =\frac{\phi-p}{1-p+p \mu}\left[\frac{1}{1-\phi+\phi \mu}-\frac{1}{\mu(\phi-p+p \phi)+p-p \phi}\right] \\
& =-\frac{(\phi-p)(\mu p(1-\phi)+(1-p)(1-\phi))}{(1-p+p \mu)(1-\phi+\phi \mu)[\mu(\phi-p+p \phi)+p-p \phi]}<0
\end{aligned}
$$

(note that $\phi-p>0$ from the definition of $p$ ), which concludes the proof that $\Theta(\mu) / q(\mu)$ is decreasing.

Next, we shall prove the first statement of the proposition. It will be convenient to restate it as $q / \Theta<\phi$ if $\mu(z) \in[0,1)$ for a strictly positive measure of $z$, or

$$
\frac{\int_{0}^{1} H(\mu(z)) d z}{\int_{0}^{1} D(\mu(z))^{\phi} d z}<\frac{H(1)}{D(1)^{\phi}} .
$$

This statement is equivalent to

$$
\frac{\int H(\mu) d \nu(\mu)}{\int D(\mu)^{\phi} d \nu(\mu)}<\frac{H(1)}{D(1)^{\phi}}
$$

where $\nu$ is a probability measure on the Borel sigma-algebra such that $\nu(\{1\})<1$. Let $h(\mu) \equiv H(\mu) / D(\mu)^{\phi}$. Then the statement can be rewritten as:

$$
\frac{\int h(\mu) D(\mu)^{\phi} d \nu(\mu)}{\int D(\mu)^{\phi} d \nu(\mu)}<h(1)
$$

Define the Borel probability measure $\nu_{1}$ by $\nu_{1}(A)=\int_{A} D(\mu)^{\phi} d \nu(\mu) / \int D(\mu)^{\phi} d \nu(\mu)$. By the change of variables theorem, the statement is equivalent to:

$$
\int h(\mu) d \nu_{1}(\mu)<\int h(\mu) d \nu_{2}(\mu)
$$

where $\nu_{2}$ is the probability measure such that $\nu_{2}(\{1\})=1$. Since $h$ is strictly increasing (from the first part of the proof), it is sufficient to show that $\nu_{2}$ first order stochastically 
dominates $\nu_{1}$ strictly. By construction $\nu_{1}([0, a]) \geq 0=\nu_{2}([0, a])$ for all $a<1$ and $\nu_{1}([0,1])=$ $\nu_{2}([0,1])=1$. Since $D(\mu)>0$ and $\nu([0, a])>0$ for some $a \in[0,1), \nu_{1}([0, a])>0=\nu_{2}([0, a])$ for some $a \in[0,1)$, which shows that $\nu_{2}$ first order stochastically dominates $\nu_{1}$ strictly, which concludes the proof.

We introduce a technical lemma, which will be useful in the proofs of Proposition 4, Lemma 1 and Lemma 2.

Lemma D.1 The functions $\theta(G)$ and $q(G)$ are continuous and $\theta(G)>0, q(G)>0, \forall G$. Also $q$ is strictly increasing in $G$.

Proof. Let $\nu$ be the probability measure on $\mu$ induced by $\underline{\mu}$. For any Borel set $A \subseteq[0,1]$, define $A^{\prime}=\{z \in[0,1]: \underline{\mu}(z) \in A\}$. Then $\nu(A)$ is equal to the Lebesgue measure of $A^{\prime}$ (which is a Borel set). Then the probability measure on $\mu$ in an economy with institutions $G$ is given by:

$$
\nu([0, a], G)=\nu\left[0, \min \left\{0, \frac{a-h(G)}{1-h(G)}\right\}\right] .
$$

Since $[0, a]$ generates all the Borel sets, we have uniquely determined $\nu(., G)$. Moreover, the CDF that $\nu(., G)$ defines is continuous in $G$, hence for any continuous function $g(\mu)$, the integral $\left.\int_{[} 0,1\right] g(\mu) \nu(d \mu, G)$ is continuous in $G$.

Then since

$$
q(G)=\left[\int_{[0,1]} D(\mu)^{\phi} \nu(d \mu, G)\right]^{\frac{1-\phi}{\phi}},
$$

$q(G)$ is continuous since $D(\mu)$ is continuous. $q(G)>0$ since for all $\mu, D(\mu)>0$. Also $q(G)$ is increasing in $G$ since $D(\mu)$ is increasing and if $G_{2}>G_{1}$ then $\nu\left(., G_{2}\right)$ first-order stochastically dominates $\nu\left(., G_{1}\right)$.

Next,

$$
\Theta(G)=\frac{\left[\int_{[0,1]} D(\mu)^{\phi} \nu(d \mu, G)\right]^{\frac{1}{\phi}}}{\int_{[0,1]} H(\mu) \nu(d \mu, G)}
$$

is continuous in $G$ since $H(\mu)>0, D(\mu)>0$ for all $\mu$. Similarly $\Theta(G)>0$.

Proof of Proposition 4. We first show that that if $\lambda \in \Omega(K, G)$ and $\lambda^{\prime}>\lambda$, then $\lambda^{\prime} \in \Omega(K, G)$. 
Let $\left\{C_{t}, K_{t+1}, G_{t+1}\right\}_{t=0}^{\infty} \in \Gamma(K, G)$ such that $\beta\left(1-\delta_{K}+q(G) f^{\prime}(K)\right) u^{\prime}\left(C_{0}\right)=\lambda$. We will construct a modified sequence $\left\{C_{t}^{\prime}, K_{t+1}^{\prime}, G_{t+1}^{\prime}\right\}_{t=0}^{\infty} \in \Gamma(K, G)$ such that $\beta\left(1-\delta_{K}+\right.$ $\left.q(G) f^{\prime}(k)\right) u^{\prime}\left(C_{0}^{\prime}\right)=\lambda^{\prime}$.

Let $G_{t}^{\prime}=G_{t}$ for all $t$. Let $C_{0}^{\prime}$ be defined by $\beta\left[1-\delta_{K}+q\left(G_{0}\right) f^{\prime}\left(K_{0}\right)\right] u^{\prime}\left(C_{0}^{\prime}\right)=\lambda^{\prime}$. By strict concavity and Inada conditions of $u, C_{0}^{\prime}$ exists and $0<C_{0}^{\prime}<C_{0}$. Define $K_{1}^{\prime}$ in such a way to satisfy the resource constraint:

$$
K_{1}^{\prime}=\Theta\left(G_{0}\right) f\left(K_{0}\right)+\left(1-\delta_{K}\right) K_{0}+\left(1-\delta_{G}\right) G_{0}-G_{1}-C_{0}^{\prime}
$$

Clearly, $K_{1}^{\prime}>K_{1}$. Then, we construct the alternative sequence recursively by (for $t=$ $1,2,3, \ldots)$ :

$$
\begin{gathered}
C_{t}^{\prime}=u^{\prime-1}\left(\frac{u^{\prime}\left(C_{t-1}^{\prime}\right)}{\beta\left[1-\delta_{K}+q\left(G_{t}\right) f^{\prime}\left(K_{t}^{\prime}\right)\right]}\right) \\
K_{t+1}^{\prime}=\Theta\left(G_{t}\right) f\left(K_{t}^{\prime}\right)+\left(1-\delta_{k}\right) K_{t}^{\prime}+\left(1-\delta_{g}\right) G_{t}-G_{t+1}-C_{t}^{\prime} .
\end{gathered}
$$

By induction, $0<C_{t}^{\prime}<C_{t}$ (because $u^{\prime}\left(C_{t-1}^{\prime}\right)>u^{\prime}\left(C_{t-1}\right)$ and $\left.f^{\prime}\left(K_{t}^{\prime}\right)<f^{\prime}\left(K_{t}\right)\right)$ and $K_{t+1}^{\prime}>$ $K_{t+1}$ (because $f\left(K_{t}^{\prime}\right)>f\left(K_{t}\right)$ and $C_{t}^{\prime}<C_{t}$ ), so the new sequence is feasible, and satisfies all constraints. Therefore $\lambda^{\prime} \in \Omega(K, G)$.

Then showing that $\Omega(K, G)=[\omega(K, G), \infty)$ is equivalent to proving that the minimization problem:

$$
\min \left\{m\left(\left(x_{t}\right), K, G\right):\left(x_{t}\right) \in \Gamma(K, G)\right\}
$$

has a well-defined solution. We will use the theorem of the maximum to prove this claim, which will also demonstrate that $\omega$ is continuous.

Endow $\Delta$ with the metric

$$
\rho\left(\left(x_{t}\right),\left(y_{t}\right)\right)=\sum_{t=0}^{\infty} 2^{-t-1}\left\|x_{t}-y_{t}\right\|_{E},
$$

where $\|.\|_{E}$ is the usual Euclidean metric. Let the $t$-section of a set $A$ be the set $\left\{x \in \mathbf{R}_{+}^{3}\right.$ : $\left.x=x_{t},\left(x_{t}\right) \in A\right\}$. Then $A$ is closed if and only if all its $t$-sections are closed. Similarly, if all $t$-sections of a set $A$ are uniformly bounded in the Euclidean metric, then $A$ is totally bounded. 
Unfortunately, $\Gamma$ is not compact-valued. We will show that without loss of generality, we can restrict $\left(x_{t}\right)$ to some $\tilde{\Gamma}(K, G)$ such that $\tilde{\Gamma}(K, G) \subseteq \Gamma(K, G)$ and $\tilde{\Gamma}$ is compact-valued and continuous.

Define the maximum sustainable capital stock $\tilde{K}$ by the solution of $f(\tilde{K})=\delta_{K} \tilde{K}$. Let $\bar{K}(K)=\max \{K, \tilde{K}\}$ and $\bar{G}(K, G)=\max \left\{G, f(\bar{K}(K)) /\left(1-\delta_{G}\right)\right\}$. Define $\bar{C}(K)=f(\bar{K}(K))+$ $\left(1-\delta_{k}\right) \bar{K}(K)$. Then for any feasible path, $0 \leq K_{t} \leq \bar{K}(K), 0 \leq G_{t} \leq \bar{G}(K, G)$, and $0<C_{t} \leq \bar{C}(K)$ are satisfied. Thus $\Gamma(K, G)$ is totally bounded.

For any feasible path, $0<q(0) \leq q\left(G_{t}\right)$ and $f^{\prime}\left(\bar{K}\left(K_{t}\right)\right) \leq f^{\prime}\left(K_{t}\right)$ are satisfied. Then if we define $z(K) \equiv \beta\left(1-\delta_{K}+q(0) f^{\prime}(\bar{K}(K))\right)$, for any feasible $\left(K_{t}, G_{t}\right), z(K) \leq \beta\left(1-\delta_{K}+\right.$ $\left.q\left(G_{t}\right) f^{\prime}\left(K_{t}\right)\right)$.

Consider a feasible policy $G_{t+1}=\left(1-\delta_{G}\right) G_{t}$. Given this sequence of $G$ and $T$, the economy has a unique equilibrium, which is continuous with respect to $\left(K_{0}, G_{0}\right)$; let period zero consumption of this equilibrium be denoted $\tilde{C}(K, G)$. Then, without loss of generality, we can ignore the elements $\left(x_{t}\right) \in \Delta$ such that $m\left(\left(x_{t}\right), K, G\right)>\beta\left(1-\delta_{K}+q(G) f^{\prime}(K)\right) u^{\prime}(\tilde{C}(K, G))$, or $u^{\prime}\left(C_{0}\right)>u^{\prime}(\tilde{C}(K, G))$ in the minimization problem. This imposes a restriction on $C_{0}$ : $u^{\prime}\left(C_{0}\right) \leq u^{\prime}(\tilde{C}(K, G))$ or equivalently

$$
C_{0} \geq \underline{C}_{0}(K, G) \equiv u^{\prime-1}\left(u^{\prime}(\tilde{C}(K, G))\right)
$$

Iterating on the Euler equation (15),

$$
\begin{aligned}
& u^{\prime}\left(C_{t}\right) \\
& \quad=\frac{u^{\prime}\left(C_{0}\right)}{\beta\left(1-\delta_{K}+q\left(G_{1}\right) f^{\prime}\left(K_{1}\right)\right) \times \beta\left(1-\delta_{K}+q\left(G_{2}\right) f^{\prime}\left(K_{2}\right)\right) \times \cdots \times \beta\left(1-\delta_{K}+q\left(G_{t}\right) f^{\prime}\left(K_{t}\right)\right)} \\
& \quad \leq \frac{u^{\prime}\left(C_{0}\right)}{z(K)^{t}} \\
& \quad \leq \frac{u^{\prime}(\tilde{C}(K, G))}{z(K)^{t}}
\end{aligned}
$$

hold, where we used the restriction of $u^{\prime}\left(C_{0}\right) \leq u^{\prime}(\tilde{C}(K, G))$. Then, without loss of generality, we can impose the restriction on $C_{t}, t=1,2, \ldots$ :

$$
C_{t} \geq \underline{C}_{t}(K, G) \equiv u^{\prime-1}\left(\frac{u^{\prime}(\tilde{C}(K, G))}{z(K)^{t}}\right) .
$$


Iterating on the Euler equation (15) once again,

$\beta\left(1-\delta_{K}+q\left(G_{t}\right) f^{\prime}\left(K_{t}\right)\right)=\frac{u^{\prime}\left(C_{0}\right)}{u^{\prime}\left(C_{t}\right) \beta\left(1-\delta_{K}+q\left(G_{1}\right) f^{\prime}\left(K_{1}\right)\right) \times \cdots \times \beta\left(1-\delta_{k}+q\left(G_{t-1}\right) f^{\prime}\left(K_{t-1}\right)\right)}$.

The right-hand side is smaller than

$$
\frac{u^{\prime}\left(\underline{C}_{t}(K, G)\right)}{u^{\prime}(\bar{C}(K))\left[\beta\left(1-\delta_{K}+q(0) f^{\prime}(\bar{K}(K))\right)\right]^{t-1}},
$$

and therefore

$$
q\left(G_{t}\right) f^{\prime}\left(K_{t}\right) \leq \frac{u^{\prime}\left(\underline{C}_{t}(K, G)\right)}{\beta u^{\prime}(\bar{C}(K))\left[\beta\left(1-\delta_{K}+q(0) f^{\prime}(\bar{K}(K))\right)\right]^{t-1}}-\left(1-\delta_{K}\right) .
$$

Since $q\left(G_{t}\right) f^{\prime}\left(K_{t}\right) \geq q(0) f^{\prime}\left(K_{t}\right)$,

$$
f^{\prime}\left(K_{t}\right) \leq \frac{u^{\prime}\left(\underline{C}_{t}(K, G)\right)}{\beta q(0) u^{\prime}(\bar{C}(K))\left[\beta\left(1-\delta_{K}+q(0) f^{\prime}(\bar{K}(K))\right)\right]^{t-1}}-\frac{1-\delta_{K}}{q(0)} .
$$

With Inada condition on the function $f(K)$, this shows that the condition $K_{t}>0$ is automatically satisfied if (11), (15) and $C_{t} \geq \underline{C}_{t}(K, G)$ are satisfied.

Then define $\tilde{\Gamma}(K, G)=\left\{\left(x_{t}\right) \in \Delta:(11),(15), C_{t} \geq \underline{C}_{t}(K, G), \forall t\right.$ for given $\left.(K, G)\right\}$. Since all the constraint functions are continuous and the inequalities are weak, all $t$-sections of $\tilde{\Gamma}$ are closed, hence $\tilde{\Gamma}(K, G)$ is closed. Since $\tilde{\Gamma}(K, G) \subseteq \Gamma(K, G)$, it is also totally bounded, hence $\tilde{\Gamma}(K, G)$ is compact-valued. Finally, since all the constraint functions are continuous, $\tilde{\Gamma}(K, G)$ is continuous. Then the rest of the proposition follows from the theorem of the maximum.

Finally, showing that $\omega$ is decreasing in $K$ is proven in the same way as proving that $\lambda \in \Omega(K, G)$ and $\lambda^{\prime}>\lambda$ implies that $\lambda^{\prime} \in \Omega(K, G)$.

Proof of Lemma 1. Since $K, G$ are fixed, the optimization problem is equivalent to maximizing consumption $C$ subject to the constraints.

$$
\begin{gathered}
\text { Define } \hat{K}^{\prime}(K, G)=\hat{G}^{\prime}(K, G) \equiv \frac{1}{3}\left[\Theta(G) f(K)+\left(1-\delta_{K}\right) K+\left(1-\delta_{G}\right) G\right] \text { and } \\
\hat{C}(K, G) \equiv \min \left\{\frac{1}{3}\left[\Theta(G) f(K)+\left(1-\delta_{K}\right) K+\left(1-\delta_{G}\right) G\right], u^{\prime-1}\left(\mathbf{v}\left(\hat{K}^{\prime}(K, G), \hat{G}^{\prime}(K, G)\right)\right)\right\} .
\end{gathered}
$$

Then (with free disposal) the triplet $\hat{C}(K, G), \hat{K}^{\prime}(K, G), \hat{G}^{\prime}(K, G)$ satisfies the constraints for $\mathbf{T}$ and is continuous. 
Then define the correspondence

$$
\hat{\Gamma}(K, G)=\left\{\left(C, K^{\prime}, G^{\prime}\right):(17), u^{\prime}(C) \geq \mathbf{v}\left(K^{\prime}, G^{\prime}\right), C \geq \hat{C}(K, G)\right\}
$$

Since $\lim _{K \rightarrow 0} \mathbf{v}(K, G)=\infty$ and for all $\left(C, K^{\prime}, G^{\prime}\right) \in \hat{\Gamma}(K, G), \mathbf{v}\left(K^{\prime}, G^{\prime}\right) \leq u^{\prime}(\hat{C}(K, G)), K^{\prime}>$ 0 is satisfied for all $\left(C, K^{\prime}, G^{\prime}\right) \in \hat{\Gamma}(K, G)$. Therefore $\hat{\Gamma}$ respects all the constraints of $\mathbf{T}$ and without loss of generality we can perform the minimization subject to $\left(C, K^{\prime}, G^{\prime}\right) \in \hat{\Gamma}(K, G)$.

Since $\left(C, K^{\prime}, G^{\prime}\right) \in\left[0, \Theta(G) f(K)+\left(1-\delta_{K}\right) K+\left(1-\delta_{G}\right) G\right]^{3}$, clearly $\hat{\Gamma}(G, K)$ is bounded. By continuity of the constraint functions, $\hat{\Gamma}$ is closed, hence compact-valued. Continuity of the constraint functions also ensures continuity of the correspondence. Then $\mathbf{T v}$ is continuous by the theorem of the maximum.

Finally, $\mathbf{T v}(K, G) \geq \beta\left(1-\delta_{K}+q(G) f^{\prime}(K)\right) u^{\prime}\left(\Theta(G) f(K)+\left(1-\delta_{K}\right) K+\left(1-\delta_{G}\right) G\right)$, so $\lim _{K \rightarrow 0} \mathbf{T v}(K, G)=\infty$ and $\mathbf{T v}(K, G)>0$.

For proving Lemma 2, we use the following results.

Lemma D.2 T $\omega=\omega$.

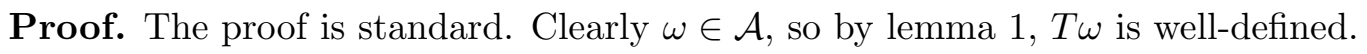

Fix $K, G$. Let $c_{0}, k_{1}, g_{1}$ be an arbitrary triplet satisfying the constraints in problem $T$ for $\omega$. Let $\left(c_{t}, k_{t+1}, g_{t+1}\right)_{t=1}^{\infty} \in \Gamma\left(k_{1}, g_{1}\right)$ such that $\beta\left(1-\delta_{k}+q\left(g_{1}\right) f^{\prime}\left(k_{1}\right)\right) u^{\prime}\left(c_{1}\right)=\omega\left(k_{1}, g_{1}\right)$. Then since

$$
u^{\prime}\left(c_{0}\right) \geq \omega\left(k_{1}, g_{1}\right)=\beta\left(1-\delta_{k}+q\left(g_{1}\right) f^{\prime}\left(k_{1}\right)\right) u^{\prime}\left(c_{1}\right)
$$

$c_{0}, k_{1}, g_{1},\left(c_{t}, k_{t+1}, g_{t+1}\right)_{t=1}^{\infty} \in \Gamma(K, G)$. Therefore $\beta\left(1-\delta_{k}+q\left(g_{0}\right) f^{\prime}\left(k_{0}\right)\right) u^{\prime}\left(c_{0}\right) \geq \omega(K, G)$. Since the triplet was arbitrary $\beta\left(1-\delta_{k}+q\left(g_{0}\right) f^{\prime}\left(k_{0}\right)\right) u^{\prime}\left(c_{0}\right) \geq \omega(K, G)$ for all $c_{0}, k_{1}, g_{1}$ that satisfy the constraints of problem $T$, so $T \omega(K, G) \geq \omega(K, G)$.

Next, let $\left(c_{t}, k_{t+1}, g_{t+1}\right)_{t=0}^{\infty} \in \Gamma(K, G)$ be arbitrary. Then $\left(c_{t}, k_{t+1}, g_{t+1}\right)_{t=1}^{\infty} \in \Gamma\left(k_{1}, g_{1}\right)$, so $\beta\left(1-\delta_{k}+q\left(g_{1}\right) f^{\prime}\left(k_{1}\right)\right) u^{\prime}\left(c_{1}\right) \geq \omega\left(k_{1}, g_{1}\right)$.

Then $u^{\prime}\left(c_{0}\right) \geq \beta\left(1-\delta_{k}+q\left(g_{1}\right) f^{\prime}\left(k_{1}\right)\right) u^{\prime}\left(c_{1}\right) \geq \omega\left(k_{1}, g_{1}\right)$; also $c_{0}, k_{1}, g_{1}$ satisfy the resource constraint and the non negativity constraints, so $c_{0}, k_{1}, g_{1}$ satisfies the constraints for $T$. Then 
$\beta\left(1-\delta_{k}+q\left(g_{0}\right) f^{\prime}\left(k_{0}\right)\right) u^{\prime}\left(c_{0}\right) \geq T \omega(K, G)$. Since $\left(c_{t}, k_{t+1}, g_{t+1}\right)_{t=0}^{\infty} \in \Gamma(K, G)$ is arbitrary, $\omega(K, G) \geq T \omega(K, G)$.

Proof of Lemma 2. The operator $T$ is clearly monotone, so $T v \geq v$ implies $T^{2} v \geq T v$ and then by induction $T^{n+1} v \geq T^{n} v$. Similarly, the assumption $v \leq \omega$ implies $T^{n} v \leq T^{n} \omega=\omega$, where we used lemma D.2. Then for any $(K, G),\left(T^{n} v\right)(K, G)$ is a monotone and bounded sequence of real numbers, hence it has a limit.

Next we show that $\lim _{n \rightarrow \infty}\left(T^{n} v\right)(K, G)=\omega(K, G)$. Fix $K, G$. Let $H_{n}$ be the policy correspondence that solves problem $T$ given $T^{n-1} v$. Let $k_{0, n}=k, g_{0, n}=G$. Then define $\left(c_{t, n}, k_{t+1, n}, g_{t+1, n}\right)$ recursively by $\left(c_{t, n}, k_{t+1, n}, g_{t+1, n}\right) \in H_{n-t}\left(k_{t, n}, g_{t, n}\right)$ if $t \leq n-1$ and $\left(c_{t, n}, k_{t+1, n}, g_{t+1, n}\right)=(0,0,0)$ if $t \geq n$.

Since $T^{n} v \leq \omega$, it follows that $c_{0, n} \geq \tilde{c}(K, G)$ for all $n$. Then by the same reasoning as in the proof of proposition $4 c_{t, n} \geq \underline{c}_{t}(K, G)$ if $t \leq n-1$.

Let $y_{n}=\left(c_{t, n}, k_{t+1, n}, g_{t+1, n}\right)_{t=0}^{\infty}$. Define

$$
\Delta_{K, G}=\left\{\left\{x_{t}\right\}_{t=0}^{\infty}, x_{t} \in[0, \bar{c}(K, G)] \times[0, \bar{k}(K, G)] \times[\bar{G}(K, G)]\right\}
$$

Then $y_{n} \in \Delta_{K, G}$ for all $n$. Since $\Delta_{K, G}$ is compact in the metric we defined above, $\left(y_{n}\right)$ has a convergent subsequence $\left(y_{n_{\ell}}\right)$ with a limit in $\Delta_{K, G}$. Denote $c_{t}=\lim _{\ell} c_{t, n_{\ell}}, k_{t+1}=$ $\lim _{\ell} k_{t+1, n_{\ell}}, g_{t}=\lim _{\ell} g_{t, n_{\ell}}$.

By construction $c_{n, t}, k_{n, t}, g_{n, t}, c_{n, t+1}, k_{n, t+1}, g_{n, t+1}$ satisfy (11), (12), (13) and (15) evaluated at $t$ if $n \geq t+1$. This fact and the continuity of constraint functions, implies that $\left(c_{t}, k_{t+1}, g_{t+1}\right)_{t=0}^{\infty}$ satisfy (11), (12), (13) and (15) for all $t$. Therefore, $\left(c_{t}, k_{t+1}, g_{t+1}\right)_{t=0}^{\infty} \in$ $\Gamma(K, G)$, so $\beta\left(1-\delta_{k} q(G) f^{\prime}(K)\right) u^{\prime}\left(c_{0}\right) \geq \omega(K, G)$.

Also by continuity $\beta\left(1-\delta_{k} q(G) f^{\prime}(K)\right) u^{\prime}\left(c_{0}\right)=\lim _{n} T^{n} v(K, G) \leq \omega(K, G)$. Then $\lim _{n} T^{n} v(K, G)=\omega(K, G)$. 